\title{
Diversitas Journal
}

ISSN 2525-5215

\section{The city in the pandemic of covid-19: the agonisation of the flaneur and the survival of the trapeiro}

\section{A cidade na pandemia da covid-19: a agonização do flâneur e a sobrevivência do trapeiro}

\author{
VIEGAS, Maria Ester Ferreira da Silva (1); AMARAL Virginia da Silva Santos ${ }^{(2)}$
}

\footnotetext{
(1)Orcid: https://orcid.org/0000-0002-8867-8259 Doutora em Geografia, Pesquisadora Associada do GOVCOPP, DCSPT, University of Aveiro-Pt, Professora Associada no Campus Arapiraca, UFAL, Alagoas, BRAZIL. E-mail: mestersilva@palmeira.ufal.br.

(2)Orcid: https://orcid.org/0000-0002-5850-8902 Doutora em Estudos Literários. E-mail: santosvirginiasilva@gmail.com

This text has as its primary purpose the discussion of the situation from the concept of cities in general. It discusses its shift from a place of consumption to a place of resilience, resulting in the flânerie's death. From a Benjaminian look, we seek to build a dialogue between Walter Benjamin's philosophy and geography and literature as a condition in the possibility of this new moment in the urban concept during the COVID-19 pandemic. We sought in Walter Benjamin's thoughts some reflections about the situation from the modern man in Charles Baudelaire's Paris, where the philosopher offers a set of images and diagrams from this contemporary and lyrical poet - fencer, bohemian, flâneur, detective, cheater, player, and prostitute. In this sense, we can then read this general concept of city and its images in this pandemic, in the poetic geography from the urban space. They are the images which form the constellation of the poet's heroic or anti-heroic task which chose the allegory as a single form of treating modernity, in this case highlighting the image of the flaneur and the rogue as the allegorist representing the modernity in the capital of consumption, the Paris from the XIX century. We then pose our look in the flâneur's image and its disappearance in the pandemic moment and the condition of resilience from the urban system and its perturbations.

\section{R E S U M O}

Esse texto tem como principal propósito discutir a situação da cidade e de sua passagem de lugar de consumo para lugar de resiliência, culminando na morte da flanérie. A partir de um olhar benjaminiano, procura-se construir um diálogo entre a filosofia de Walter Benjamim, a Geografia e a Literatura como uma condição de possibilidade desse novo momento do urbano durante a pandemia da Covid-19. Buscou-se, no pensamento de Walter Benjamim, algumas reflexões acerca da situação do homem moderno na Paris de Charles Baudelaire, em que o filósofo oferece um conjunto de imagens e diagramas desse poeta lírico moderno - esgrimista, boêmio, flâneur, detetive, trapeiro, jogador e prostituto -, a fim de que possamos ler a cidade e suas imagens, nesse momento de pandemia, na geografia poética do espaço urbano. Elas são as imagens que formam a constelação da tarefa heroica ou anti-heroica do poeta que elegeu a alegoria como a forma singular de tratar da modernidade, nesse caso ressaltando a figura do flâneur e do trapeiro como o alegorista representante da modernidade na capital do consumo, a Paris do século XIX. Assim, pousaremos o olhar na figura do flâneur e no seu desaparecimento no momento pandêmico e na condição de resiliência do sistema urbano e as suas perturbações.

\section{ARTIGO}

Histórico do Artigo:

Recebido: 30/04/2021

Aceito: 10/12/2021

Publicação: 01/01/2022

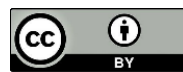

\author{
Keywords: \\ City. Modernity; Merchandise; \\ Capitalism. \\ Palavras-Chave: \\ Cidade. Modernidade. \\ Mercadoria. Capitalismo.
}




\section{Introdução}

Este artigo objetiva uma aproximação da Geografia e da Literatura, focando na leitura dos espaços e dos lugares, das paisagens e das territorialidades, fazendo uso do simbólico e do imagético, por meio de alguns textos literários. Entendendo que a Geografia e a Literatura são "uma narrativa do mundo", a Geografia do mesmo modo que a Literatura faz uso de categorias espaciais e de atores sociais que se completam. Assim, neste atual momento de crise sanitária mundial, a reflexão sobre a capacidade da mobilidade das pessoas se tornou uma preocupação emergente naqueles que lidam com a ciência geográfica, com a sociologia, com a antropologia e com o urbanismo.

Como entender a cidade nesse momento? Como as pessoas (atores sociais) estão se organizando para essa "mobilidade zero"? Como estão reagindo diante dessa impossibilidade de caminhar livremente pela cidade? O que nos diz a literatura para nos confortar ou aprofundar a nossa reflexão nesse momento de desconforto psicossocial que enfrentamos? Onde buscar a resiliência necessária para atravessar essa crise mundial?

Em tempos de pandemia, a resiliência é, talvez, mais do que nunca, a noção mais adequada para pensarmos os lugares que habitamos, aqueles que sonhamos serem inteligentes, sustentáveis e, tanto quanto possível, capazes de nos adaptarmos a diferentes tipos de rupturas. Porém, essa resiliência não será uma resiliência ligada a objetos técnicos e maquínicos ligados à gestão digital dos fluxos de dados; ela deverá ser mais voltada ao caráter humano que adquire com a crise da saúde. Estaremos, portanto, tentando dialogar sobre uma ideia de "resiliência humana".

A palavra "resiliência" é originária das ciências exatas, mais precisamente da Física, em que seu significado pode ser entendido como a capacidade de resistência de um corpo ou material ao impacto ou deformação. No entanto, o campo semântico da palavra é estendido a outras disciplinas: sociologia, ecologia, psicologia, geografia. Em sentido amplo (e em particular no que diz respeito às ciências humanas), podemos considerar resiliência como a capacidade, para um determinado sistema, de ultrapassar as alterações provocadas por um ou mais elementos perturbadores, de regressar ao seu estado inicial e/ou operação normal. Das diferentes formas de resiliência que a semântica pode açambarcar, a resiliência urbana será a forma que usaremos para ler a condição das cidades dentro do evento pandêmico da Covid-19. O conceito de resiliência reexamina a forma de pensar sobre o sistema urbano e suas perturbações.

Aplicada à cidade, a resiliência pode ser definida como a capacidade de um sistema urbano de absorver uma perturbação e retomar suas funções após essa perturbação. A 
operacionalidade do conceito passaria pela necessidade de adaptar o funcionamento do sistema urbano, bem como seus componentes às perturbações potenciais, para reconstruir o sistema urbano após uma grande perturbação ou para definir métodos de gestão de crise, integrando o mundo complexo da cidade. $\mathrm{O}$ conceito de resiliência aplicado à cidade deve encontrar traduções operacionais, nomeadamente ao nível dos serviços urbanos, que também vão ao encontro dos objetivos da sustentabilidade. Desse modo, a resiliência se insere como condição inerente ao processo pandêmico, pois, para poder seguir adiante dentro do "novo normal", a população introjetou (não sem uma resistência de determinados segmentos e setores) uma espécie de defesa natural ao novo comportamento solicitado e orientado pelas autoridades públicas. Velhos hábitos cotidianos de flanar pela cidade, "lécher les vitrines", beber um café em um bar pitoresco no fim da jornada, tomar um chope com amigos depois do expediente, tudo isso é interditado, e o que se propõe no lugar é a máxima: "não muito perto de seu vizinho, não muito longe de casa". A regulação das distâncias molda a nossa vida diária nessas horas de controle sobre as interações sociais e também com metros e metros quadrados em que os modelos epidemiológicos tentam explicar a propagação do vírus: densidade das cidades, intensidade de uso dos espaços coletivos, ocupação das moradias...

Nesse artigo procuramos dialogar, com base em algumas discussões de Benjamim (1989), sobre o fenômeno da metrópole moderna, em que ele discute as grandes cidades (Paris, Berlim, Moscou etc.), entre o período de duas guerras mundiais. Segundo os autores utilizados nessa reflexão, Benjamim coloca frente a frente o contraditório da modernidade. De um lado, os ideais da modernização e do progresso; de outro, a barbárie em sua forma mais cruel: a pobreza, a miséria, a doença, os graves problemas econômicos que assolavam a humanidade inteira, os valores humanísticos em descréditos, uma decadência em toda parte da ética política, o aumento da violência e da destruição. Então, nesse sentimento de estarmos na mesma estrutura psicossocial da qual Benjamim construiu os seus livros as Passagens, Charles Baudelaire um lírico no auge do capitalismo, tentaremos nos aproximar dessa experiência urbana caótica que Benjamim descreveu no século XX que nos parece tão atual e familiar.

A aproximação com obras literárias irá nos ajudar a revelar a nova fisionomia da cidade, construindo uma imagem da cidade por meio dos fragmentos das obras que irão falar do flâneur e de sua paixão pelas mercadorias (neste momento atual do século XXI, agora impedido pelo novo coronavírus). Enaltecida dentro dos textos de Baudelaire e Benjamim, a figura do flâneur tenta sobreviver a esse segundo embate. Como no primeiro foi derrotado pelo consumo e pela obsessão pelo trabalho, passear teria ficado "fora de moda", senão impossível. Atualmente, a possibilidade de voltarmos ao tempo da flanérie nos parece que deixou de existir, pois se antes do momento pandêmico a figura do flâneur estava seguramente ameaçada pela tela do celular, 
onde as pessoas tinham seus olhos fixos e não mais no mundo circundante, no atual momento, o celular parece-nos a única forma possível de se manter em diálogo com o mundo, liquidando, assim, de forma fatal com uma das figuras mais belas da poética da cidade, enaltecida por Baudelaire (1985) no poema As flores do mal: o flâneur, ou vagabundo. Será, por ventura, que a figura do flâneur se desmaterializou, estando preso às páginas da web, de um site a outro?

Ao ouvir um podcast do sociólogo David Breton (2020) sobre a importância de caminhar, ação que não pode ser substituída pelo passeio digital, ele diz que isso não pode acontecer, porque passear na sua essência envolve o corpo, a sensorialidade, as emoções e a curiosidade, sendo uma postura criativa perante o mundo, afirma ele, uma postura que deixa vestígios de memória e suscita encontros. Logo, fazer ressuscitar o flâneur é um ato de resistência, não devemos deixar que os écrans dos celulares capturem nossas vidas. Nas palavras de David Breton $^{1}$ (2020): "passear desvia-se dos princípios de velocidade, rendimento, utilidade, lucro, disponibilidade etc" que assombram nossas sociedades contemporâneas. Assim, abre-se uma divergência dos valores neoliberais que nos governam. Então, nesta pandemia, onde situamos o homem trabalhador que precisa do cotidiano para sua sobrevivência material e não de um passeio para alimentar as suas subjetividades? O que resta da cidade para as pessoas que não podem ficar reclusas? Para elas, digital não faz e nunca fez parte do seu mundo. Para além da segunda morte do flâneur, a pandemia vem revelar com mais clareza as grandes diferenças sociais que existem dentro do universo da metrópole.

\section{A cidade como lugar de consumo e agonização do flâneur}

A construção da noção de flâneur em W. Benjamim em meados do fim do século XIX é comumente utilizada para designar pessoas (poetas e intelectuais, primordialmente) que usam a cidade como um laboratório de comportamentos, no qual a prática da observação é a principal ocupação do flâneur. A flânarie (a prática de vagar pelas ruas, becos, praças, galerias, cafés, bares e parques) sempre deteve o interesse dos estudiosos da filosofia, da literatura, da sociologia, da antropologia urbana e da geografia, haja vista que se constitui numa ferramenta importante de leitura dos movimentos dos citoyens e das relações sociais resultantes desses movimentos. $\mathrm{O}$ nascimento do flâneur está associado à transformação do espaço urbano, ao surgimento das galerias, que são "caminhos cobertos de vidro e revestidos de mármore, através de blocos de casas, cujos proprietários se uniram para tais especulações” (BENJAMIM, 1989, p. 35). A

\footnotetext{
${ }^{1}$ LE BRETON, D. Le marcheur: Laure Adler. À retrouver dans l'émission Horschamps par Laure Adler. France Culture, lundi 25, mai 2020. Podcasts. Disponível em: https://www.franceculture.fr/emissions/horschamps/david-le-breton. Acesso em: 09 ago. 2020.
} 
flânerie se desenvolve com a presença das galerias, segundo Benjamim, jamais teria se desenvolvido em toda sua plenitude sem elas. O flâneur é um tipo criado por Paris, foram os parisienses que fizeram de Paris a terra prometida do flâneur (BENJAMIM, 1989, p. 186). O flâneur sente-se em casa no meio da paisagem de galerias e da multidão (BENJAMIM, 1989, p. $35)$.

Para Nuvolati (2009), citando Bauman (1999), o flâneur é uma figura típica da pósmodernidade, bem como o vagabundo, o turista e o jogador. O flâneur continua a ser um símbolo da incerteza, de relações episódicas e fragmentárias que vivencia a vida urbana (NUVOLATI, 2009). Ainda com Nuvolati (2009), temos que as diferentes visões sobre o uso contemporâneo do conceito de flâneur são diversas; é ainda o flâneur um animal urbano por excelência. Sua escola, a vida metropolitana, simbolizando um leque de coisas diferentes, entre elas, a rebelião contra o consumo de massa, especialmente o turismo, o flâneur deseja um modo de vida mais lento, longe da determinação do ritmo acelerado do capital, do apito da fábrica. Porém, o ritmo da cidade logo será alterado pela dinâmica da produção que exige pressa e rapidez, em que tempo é sinônimo de dinheiro. A grande loja é o derradeiro refúgio do flâneur, onde ele vaga no labirinto das mercadorias como anteriormente vagava no interior dos labirintos urbanos.

Para Santos Neto (2007), em Baudelaire, o flâneur é o "homem das multidões", diferente de Poe que considera a multidão somente como uma espécie de refúgio para o homem antissocial e suspeito, afirma Santos Neto (2007 p. 59). Baudelaire amava a solidão, "mas a queria na multidão" a multidão era remédio para o seu tédio. A atividade do flâneur é feita a pé, ele se locomove dentro da cidade, combinando três atividades: caminhada, observação e interpretação. Andar na cidade remete a uma condição de solidão e liberdade na recusa de velocidades e percursos impostos pelo ritmo urbano massificado: é a escolha do tempo e das rupturas pessoais que, ao mesmo tempo, representa uma abertura para os outros. $\mathrm{O}$ ato de caminhar pode ser visto como uma prática que tende a socialização dos locais e em locais públicos, é o principiar da construção da cidadania, de ser cidadão, de viver a cidade na cidade e não apenas em lugares privados. O uso dos espaços públicos enriquece as experiências relacionais. Para Nuvolati (2009), o conceito de flâneur, deslocados das arcadas parisienses, para os subúrbios e centros comerciais contemporâneos, parece refletir a confusão do nosso tempo, e a sede de novas relações com os lugares e seus habitantes.

A interdição desses espaços por questões sanitárias ocasiona diferentes transtornos à população, daí falarmos em uma nova "resiliência urbana" com um caráter mais humano e menos técnico. O que estamos tentando trazer à discussão é exatamente esse desconforto causado pela pandemia que interrompe hábitos que com a crise pandêmica, e a degradação já causada pelo avanço do capital, tornou insuportável o ambiente citadino, obrigando os gestores 
públicos a ver e a agir, reconhecendo nas suas cidades os diferentes grupos vulneráveis que a compõem. A crise sanitária veio para escancarar as diferenças sociais gritantes dentro de nossas cidades. A interdição, o afastamento, a suspensão das atividades laborais e estudantis revelaram o profundo abismo que separa as pessoas dentro de uma mesma cidade.

Aqueles que podem ficar em suas casas, como o burguês que evita a multidão, na análise W. Benjamim, para compensar esse afastamento da rua, ele confecciona e reproduz todo o mundo antes das mudanças que a modernidade trouxe consigo. Segundo Benjamin (1989) citado por Santos Neto (2007) o rompimento do flâneur com o isolamento insensível do burguês é somente aparente. Desde a época de Luis Felipe, a burguesia francesa buscou uma compensação pelo desaparecimento dos seus vestígios privados no espaço da grande cidade, por isso ela valoriza as quatro paredes da sua casa como seu último reduto, em que tenta imprimir os seus vestígios nos objetos que constituem o seu habitat, assim "tira o molde de uma multidão de objetos; procura capas e estojos para chinelos e relógios de bolso, para termômetros e portaovos, para talhares e guarda-chuvas. Dá preferência a coberturas de veludo que guardam a impressão de toda conta” (BENJAMIM, 1989 apud SANTOS NETO, 2007, p.59).

Nesse momento, aqueles que podem se isolar da vida cotidiana em suas casas, se conectando com os outros por meio do mundo digital, reproduzem o comportamento do homem burguês, que mesmo isolado se conecta com o mundo (que ele foi obrigado a abandonar com o avanço do capital e as reformas urbanas), assim a classe média e a alta se organizam dentro do mundo digital ou mesmo indo em busca de refúgios isolados em casas de campo e de praia. O trabalhador nada pode fazer, senão, descumprindo as ordens sanitárias, mas não por motivos poéticos ou filosóficos, e sim de sobrevivência material, vai às ruas em busca do seu cotidiano, agora em vias de destruição por motivo pandêmico.

Torna-se, então, imperioso pensar em um espaço público onde várias figuras da comunidade, inclusive o trapeiro (catador de lixo), o entregador de alimentos e remédios, pensando os lugares, a sociedade como um todo de múltiplas perspectivas. Garantir a mobilidade de pedestres, de ciclistas (agora na pandemia a bicicleta é um dos meios de locomoção mais indicado para evitar a proximidade). A situação pandêmica nos convida a uma reflexão profunda sobre a ideia da cidade que queremos. Nos convida a pensar em propostas de requalificação urbana que respeitem as tradições e a cultura local garantindo a segurança e a "habitabilidade dos bairros" a qualquer hora do dia. Nessa pandemia, temos o desenho claro dos lugares da cidade onde não poderemos de forma alguma circular devido ao aglomerado de pessoas e de habitações que de forma alguma asseguram a distância exigida nos protocolos de orientação sanitária, a exemplo dos conjuntos habitacionais classificados de urbanismo insurgente, as favelas, que se tornaram um grande vetor de retroalimentação da covid-19. 


\section{A cidade como lugar de consumo e a morte do flâneur}

"O que são os perigos da floresta e da padaria comparados com os choques e conflitos diário do mundo civilizado".

(Benjamim, 1989, p. 37)

É impressionante observar como as estruturas perversas da sociedade capitalista, principalmente ao nível da nossa, criam as condições materiais que geram de um lado sofrimentos tão profundos nas classes populares, negando a elas o direito de expressá-los; de outro, nas classes dominantes, a certeza de que aquelas são insensíveis, são gente bruta, que nada sabe, nem mesmo sofrer.

Existe uma humanidade acuada pelo Estado, uma sociedade dividida entre opressores e oprimidos, em que esta mesma humanidade mergulhada em sombras por toda parte. Além disso, a devastação da natureza é uma constante e é uma só, sendo, como afirma Marcuse (1973), proveniente da lógica do capital:

A poluição e o envenenamento são dados mentais e estatísticos, subjetivos e objetivos. Marcuse (1973) nos convida a refletir quando diz que a luta por um ambiente que assegure uma vida mais feliz poderia reforçar, nos próprios indivíduos, as raízes instintuais da sua própria libertação. Se os homens já não são capazes de distinguir entre o belo e o hediondo, entre a calma e o barulho, já não conhecem a qualidade essencial da liberdade, da felicidade. $\mathrm{O}$ uso da natureza enquanto mercadoria na medida em que ela se torna no ambiente do capital mais do que no do homem, a natureza acaba por fortificar a servidão humana. Estas condições têm a sua origem nas instituições de base do sistema estabelecido para o qual a natureza é primeiramente o objeto da exploração útil. (MARCUSE, 1973, p. 57).

Aqui ao introduzir esta problemática da ecologia por meio de Marcuse (1973), a intenção é recorrer a Marx, que nos diz: "o sistema capitalista é um esbanjador de homens, de trabalho vivo, um dilapidador de carne e sangue, bem como de nervos e de cérebros” (MARX, 1959, p, 101). É nas cidades, principalmente nas grandes metrópoles, que o regime capitalista de produção se revela em todo o seu antagonismo e contradições. Essas observações foram palmilhadas por escritores que escreveram sobre o olhar da filosofia e da literatura a problemática do homem moderno nas grandes cidades. A palavra de Walter Benjamim sobre essa temática é oportuna, porque descreve e explica a razão última da degradação do humano nas grandes cidades onde o impacto do sistema é visível a olho nu.

A cidade como palco dessa degradação é marcada desde o início da produção industrial no seu uso, com o sinal de miséria e da sujeira. Observam-se as marcas da miséria no urbano, na poética do romance de Dickens, em que, ao descrever Birmingham, ressalta esse lado perverso da devastação da natureza e da humanidade. 
Essa degradação do humano seria vista em sua forma absoluta nas grandes cidades, nas metrópoles, onde as fantasmagorias da modernidade se apresentam em sua forma mais crua, em que, segundo Bolle (2000), a metrópole seria uma categoria do imperialismo oitocentista e que, nas vitrines das metrópoles, o consumidor, como um príncipe, tem aos seus pés a abundância das mercadorias de todos os países do mundo. A essa mitologia da metrópole, Benjamim contrapõe uma outra visão da cidade como uma forma de despertar outras visões dessa mesma cidade:

Seja qual for o partido a que se pertence [...] é impossível não ficar comovido com o espetáculo dessa multidão doentia, que traga a poeira das fábricas, inspira partículas de algodão, se deixa penetrar pelo alvaiade, pelo mercúrio e todos os tóxicos usados na fabricação de obrasprimas [...]. Essa multidão se consome pelas maravilhas, as quais, não obstante, a Terra lhe deve. Ela sente correr em suas veias um sangue púrpura e lança um olhar demorado e cheio de tristeza sobre a luz do Sol e a sombra dos grandes parques [...] (BOLLE, 2000, p. 29)

O contraste aqui descrito entre a população miserável da periferia e do luxo e resplendor da capital se reproduz em escala maior entre os países metropolitanos, os que dominam a economia mundial e os periféricos.

A metrópole na visão benjaminiana teria em Paris a capital símbolo da modernidade, como símbolo das primeiras exposições universais, "capital do luxo e da moda", centro de planejamento da industrialização da Terra, palco da Exposição Universal de 1967, com o desabrochar radioso da cultura capitalista (BOLLE, 2000, p. 29).

Em sua obra, Baudelaire - um lírico no auge do capitalismo, Walter Benjamin, como um perfeito alegorista junta os fragmentos para nos oferecer as imagens do autor de "As flores do mal", que são arquétipos extraídos do espaço topográfico que constitui a modernidade. A metrópole moderna é o lócus de manifestação do mundo das fantasmagorias, da multidão, inclusive do proletariado, que vai se encantar com o universo das galerias e vitrines, e suas feiras internacionais que serviam para exibir o mundo das mercadorias e escamotear o conflito entre as classes sociais (SANTOS NETO, p. 54-55). Nesse espaço topográfico, a atividade do poeta lírico será comparada com as diferentes atividades dos homens que constituem o mundo da metrópole: flâneur (vagabundo), trapeiro (lixeiro), prostituta, jogador, boêmio, detetive e esgrimista. No texto que segue, centrar-me-ei na figura do flâneur e do trapeiro, figuras essas pelas quais Walter Benjamim mostra os conflitos sociais que envolvem a cidade, as situações de revolta e revolução. É claro que essa apreciação não se esgota aqui, mas é uma tentativa de um outro olhar sobre o urbano em que se condensa a literatura, a história e a geografia. 


\section{A cidade como lugar de consumo e a emergência do trapeiro}

A reificação do humano começa quando tudo se torna passível de troca, onde a ideia de humanidade se esvazia, sendo ocupada pelas relações desagregadoras de consumo. A mercadoria sendo destituída por completo de seu valor de uso, exposta nas vitrines, faz do fetiche sua arma letal. Para Santos Neto (2007) citando Benjamim (1989), o trapeiro é resultante do processo de crescimento da cidade, que lança na periferia uma multidão de homens que são obrigados a viver em permanente estado de miséria, sendo obrigados a exercerem qualquer atividade laboral para sobreviver. Essas pessoas dentro de uma análise desse momento pandêmico podem ser lidas como "os sempre vulneráveis". Esses trabalhadores qualificados como "sempre vulneráveis" são aqueles que estão no grupo das pessoas que, não podendo trabalhar remotamente, muitas vezes estão contratados como empregados temporários, sejam operários de indústrias e da construção, marítimos, pescadores, entregadores de Ifood, catadores de "latinhas" e papelão, motoristas de Uber, empregados administrativos e domésticos. Sua vulnerabilidade econômica está ligada à precariedade de seu status, pois não podendo trabalhar em casa, resta a "rua" como lugar de sobrevivência, pois sofrem de fragilidade financeira, com média salarial abaixo da média de $\mathrm{R} \$ 928,00$ reais mensais por pessoa, sofrem psicologicamente e fisicamente.

O trapeiro (vulnerável na sua essência) é o homem encarregado de apanhar tudo o que a cidade rejeitou, tudo o que ela desdenhou, tudo o que ela quebrou. Ele cataloga e coleciona. Ele opera a escolha inteligente dos objetos como o homem avaro cuida do tesouro. Desse modo, as imundícies da cidade recuperam seu valor de troca e de uso. O trapeiro não pode ser incluído na boêmia, no entanto "desde o literato até o conspirador profissional, cada um que pertence à boêmia podia encontrar no trapeiro um pedaço de si” (BENJAMIM, 1989 apud SANTOS NETO, 2007, p. 66). Pois, cada um deles tem dentro de si um protesto velado contra a sociedade. O trapeiro não está sozinho em sentimento de revolta contra a ordem estabelecida. O poeta e o trapeiro estão reunidos, escreve Benjamin: "a escória diz respeito a ambos; solitários, ambos realizam seu negócio nas horas que os burgueses se entregam ao sono; o próprio gesto é o mesmo em ambos" (BENJAMIM, 1989 apud SANTOS NETO, 2007, p. 66). O poeta erra pela cidade à cata de rimas, como o trapeiro que se detém no caminho para recolher o lixo que o faz tropeçar nas ruas da cidade. Segundo Benjamim o maior número de trapeiros surgiu nas cidades graças aos novos métodos industriais. Os rejeitos ganharam um certo valor, trabalhando para intermediários, "representavam uma espécie de indústria caseira situada na rua" (BENJAMIM, 1989, p. 16). O trapeiro quando surge, é uma figura que deslumbra os investigadores do pauperismo, que estupefados com essa nova figura criada pelo capitalismo se 
questionam "onde seria alcançado o limite da miséria humana" classificando-os como "as classes perigosas da população" (BENJAMIM, 1989, p. 16). Ele vive das sobras daquilo que não pode consumir, vive do resto da classe burguesa que consome tudo desenfreadamente. Vive dos restos que agora já escassos, porque a crise sanitária obrigou uma redução abrupta do ato de consumir, já escasso porque a pandemia obrigou a não consumação das coisas, dos lugares, das pessoas, da vida em comunidade. Ao contrário do flâneur, o trapeiro é uma figura que veio para ficar. Ele é produto desta sociedade de consumo. Ele é o "limpador" da cidade, recolhendo as sobras de algo que ele não pôde usufruir, vivendo às margens da sociedade, mas inserido nela pela marginalidade do capitalismo selvagem.

\section{À guisa de conclusão}

A representação benjaminiana da metrópole configura-se como uma obra aberta para um diálogo com as culturas na periferia do capitalismo. Fiz uma tentativa de mostrar que é possível estabelecer um diálogo profícuo entre a filosofia de Walter Benjamim e a Geografia, principalmente se a discussão girar em torno das cidades, símbolo máximo da criação humana e repositório de excelência da criação do homem, tanto as suas maravilhas (estradas, ruas, pontes, galerias, túneis), quanto as suas mazelas, suas dores (a multidão incerta, as favelas, os bêbados, os jogadores, as prostitutas, os trapeiros).

Todas essas figuras se objetivam na cidade, porque a cidade é por excelência o lugar da "troca", é o locus das relações sociais de produção objetivadas nas diferentes formas que nos oferece a paisagem. A noção de flâneur, criada por Benjamim na Paris do século XIX para designar poetas e intelectuais que, ao caminhar, observam criticamente as cidades, os indivíduos. Será sempre uma ferramenta privilegiada para identificar os modos de movimento e exploração dos lugares pelos indivíduos e pelas descobertas dos problemas sociais que a cidade apresenta. O flâneur é um excelente leitor do espaço urbano, pois como um profundo usuário do espaço em termos físicos e intelectuais, é importante observá-lo no desenvolvimento dos espaços coletivos. A pandemia, pois, coloca em vias de extinção o hábito de passear, de forma gradual pela cidade, de pessoas que usam os cafés com seus laptops para trabalhar, de consumir a cidade de forma mais livre... aguardemos e fiquemos atentos ao surgimento do flâneur digital. 


\section{Referências}

BAUDELAIRE, C. As flores do mal. Tradução de Ivan Junqueira. Rio de Janeiro: Nova Fronteira, 1985.

BAUMAN, S. La società dell'incertezza. Bologne: Mulino, 1999.

BENJAMIN, W. Charles Baudelaire um lírico no auge do capitalismo. Tradução de José Carlos Martins Barbosa e Hemerson Alves Baptista. São Paulo: Brasiliense, 1989. V. 3

BENJAMIN, W. Magia e técnica, arte e política. Tradução de Sergio Paulo Rouanet. São Paulo: Brasiliense, 1994.

BENJAMIN, W. O Narrador. In. BENJAMIN, Walter. Os pensadores. Tradução de Modesto Carone. São Paulo: abril Cultural, 1980.

BENJAMIN, W. O Trabalho das passagens. Tradução de Sônia Campaner Miguel Ferrari. Cadernos de filosofia alemã, v. 3, 1997.

BENJAMIN, W. Origem do drama barroco alemão. Tradução de Sérgio P. Rouanet. São Paulo: Brasiliense, 1984.

BOLLE, W. Fisiognomia da Metrópole Moderna: representação da História em Walter Benjamim. São Paulo: Editora da Universidade de São Paulo, 2000.

BOURDIN, A. La ville malade du coronavirus. 2020. Disponível em:

http:/ /www.riurba.review/2020/04/la-ville-malade-du-coronavirus/. Acesso em: 2 abr. 2020.

DICKEN, C. As aventuras de Pickwick. Porto Alegre: Globo, 1951.

DINIZ, D. de O. Walter Benjamin e as Passagens: uma narratividade poética do histórico. Cadernos Benjaminianos, n. 1, p. 74-93, dez. 2019. Disponível em:

http://www.periodicos.letras.ufmg.br/index.php/cadernosbenjaminianos/article/view/5303/4711. Acesso em: 07 set. 2020.

GAGNEBIN, J. M. História e narrativa em Walter Benjamin. São Paulo: Perspectiva, FAPESP; Campinas: Editora da Universidade Estadual de Campinas, 1994.

LE BRETON, D.. Le marcheur (Loucação de ) : Laure Adler. À retrouver dans l'émission Horschamps par Laure Adler. France Culture, lundi 25, mai 2020. Podcasts. Disponível em: https://www.franceculture.fr/emissions/hors-champs/david-le-breton. Acesso em: 09 ago. 2020.

MARCUSE, H. et al. Ecologia e revolução. Ecologia contra poluição. Lisboa: Dom Quixote, 1973.

MARX, C. El capital. México: Fondo de Cultura Econômica, 1959.

MARX, K. Manifesto do partido comunista. Obras escolhidas. São Paulo: Alfa - Omega, [s.n.].

MISSAC, P. Passagem de Walter Benjamin. Tradução de Lílian Escorel. São Paulo: Iluminuras, 1998.

NUVOLATI G. Le flâneur dans l'espace urbain.Géographie et cultures, v.70, 2009. Disponível em: URL:http://journals.openedition.org/gc/2167. Acesso em: 02 out. 2020.

SANTOS NETO, A B. dos. A interpretação alegórica do mundo da filosofia de Walter Benjamim. Maceió: EDUFAL. 2007

SANTOS, P. da S. Benjamin e Kracauer: elementos de uma epistemologia de "trapeiros". Sociol. Antropol. v. 3, n. 6, p. 489-508, dez. 2013. Disponível em: 
http:/ / www.scielo.br/scielo.php?script=sci_arttext\&pid=S223838752013000600489\&lng=en\&nrm=is o>. Acesso em: 07 set. 2020.

TOUBIN, M. et al. La Résilience urbaine: un nouveau concept opérationnel vecteur de durabilité urbaine ? Développement durable et territoires, v. 3, n. 1, maio 2012. Disponível em: http://journals.openedition.org/developpementdurable/9208.Acesso em: 28 out. 2020. 